\title{
"A menor distância entre dois pontos...": sobre o conceito de dobra enquanto componente da visão de mundo e da técnica de escrita em Maria Gabriela Llansol
}

\author{
Aderaldo Ferreira de Sousa Filho \\ (Universidade Federal Fluminense)
}

\section{RESUMO}

Neste artigo, propomos uma leitura do processo de escrita de Maria Gabriela Llansol a partir do conceito de dobra, tal como desenvolvido por Deleuze em A Dobra, Leibnize o Barroco. Este conceito remete a um traço característico do Barroco, mas que pode, contudo, ultrapassar seus limites históricos. No Barroco, a dobra define tanto um recurso estético como uma componente de sua visão de mundo, pois garante um efeito de imanência que contradiz tradicional oposição entre o material e o imaterial, entre o visível e o inteligível. $\mathrm{Na}$ escrita da autora portuguesa, a dobra se nos apresenta como um elemento fundamental, tanto na caracterização de sua visão do mundo como na técnica que ela desenvolve, opondo a textualidade à narratividade. Assim, o conceito resumiria a percepção do real através das dobras que esta escrita evoca, assim como o que a autora caracteriza como a técnica da sobreimpressão, na qual a linguagem abriria caminho a diversos níveis de realidade, unindo-os e indiscernindo seus limites, tal como o Barroco faz com o plano divino e o terreno. Procuramos demonstrar ainda como este conceito se aplica à própria escrita, a partir da proliferação de imagens (que a autora opõe a metáfora) que configura as cenas fulgor.

PALAVRAS-CHAVE: Llansol; dobra; Barroco.

\section{ABSTRACT}

This article proposes a particular reading of Maria Gabriela Llansol's writing process based on the concept of the fold as developed by Deleuze in The Fold, Leibniz and the Baroque. This concept addresses to a peculiar baroque trait which is able, however, to surpass its historical boundaries. In the baroque, the fold defines an aesthetic resource as well as a component of its human perspective, for it grants an immanence effect that contradicts the traditional opposition between the material and the immaterial, between the visible and the intelligible. In the Portuguese author's writing the fold is presented as a fundamental element regarding both the characterization of her human perspective and the technique she develops, opposing textuality and narrativity. The concept, therefore, would summarize the perception of reality through the folds this writing evokes such as what the author's characterizes as the over-impression through which the language would open way to several levels of reality, binding them and undiscerning their limits, just as the baroque does with the divine and the mundane. Evidence of how this concept can be applied on writing itself, through the proliferation of images (opposed to metaphor by the author) that sets the flashier scenes.

KEYWORDS: Llansol; fold; Baroque. 
Apesar de o Barroco ser muitas vezes caracterizado por tirar seus efeitos de contrastes, criando uma constante tensão antitética, este processo não se verifica num dos pontos fulcrais de sua visão de mundo: a relação entre o corpo e a alma, entre o sensível e o inteligível, entre o mundo terreno da physis e um mundo que o transcenda. É que o Barroco, em sua tentativa de restaurar a razão clássica, instaura uma vasta zona de imanência, tornando esta relação muito mais próxima de uma síntese que de uma antítese, sobreimprimindo (se convém aqui usar uma terminologia llansoliana) os dois planos num mesmo, apesar de respeitar ainda a transcendência de uma entidade divina. É segundo esta perspectiva que o Barroco nos parece próximo tanto de nossa contemporaneidade, já que esta nega a transcendência, sobretudo no plano epistemológico e estético, como da escrita de Maria Gabriela Llansol por configurar a simultaneidade de diversos planos, tais como os do nosso universo interior e os das virtualidades históricas que transbordam nossa realidade visível: os existentes-não-reais.

No entanto, a relação entre a cosmovisão barroca e a llansoliana demanda, de imediato, algumas considerações. Em primeiro lugar, a linhagem da autora, entendida como uma continuidade de problemática, tem sua origem em místicos da Idade Média e filósofos árabes da mesma época. Em segundo, há de se considerar, já que o trabalho propõe uma leitura de Llansol através de um conceito de Deleuze, que a autora elege Espinosa como uma de suas principais figuras e o opõe a Leibniz que, segundo o filósofo francês, é quem melhor traduz a cosmovisão barroca. Se, contudo, a cosmovisão llansoliana não é essencialmente barroca, há de se considerar que o Barroco não remeteria "a uma essência, mas sobretudo a uma função operatória, a um traço. Não pára de fazer dobras." (DELEUZE, 2007, p. 13) É a dobra que se multiplica ao infinito, em suas duas extremidades; que vai da matéria à alma, tornando indiscernível o limite entre o sensível e o inteligível. A dobra, além de permitir a caracterização de um elemento barroco fora de seus liames históricos, atua, enquanto procedimento estético, como a expressão do imanentismo característico do Barroco. Nosso trabalho pretende, portanto, demonstrar como a escrita de Llansol é composta por dobras e como estas são um elemento essencial da expressão de sua singular visão de mundo.

Deleuze se vale da alegoria da casa barroca, repartida em dois andares, para ilustrar a relação de sobreimpressão entre o material e o imaterial, típica do período. Para o Barroco, a alma é projetada no corpo, sendo dele inseparável e mantendo com ele uma relação complexa:

O que é propriamente barroco é essa distinção e repartição de dois andares. Conhecia-se a distinção de dois mundos em uma tradição platônica. Conhecia-se o mundo de inúmeros andares, composto segundo uma descida e uma subida que se enfrentam em cada andar de uma escada que se perde na eminência do Uno e se desagrega no oceano do múltiplo: o universo em escada da tradição neo-platônica. Mas o mundo com apenas dois andares separados pela dobra que repercute dos dois lados segundo um regime diferente, é a contribuição barroca por excelência. Ela expressa (...) a transformação do cosmo em mundus. (DELEUZE, 2007, p. 57)

Trata-se, portanto, de uma cosmovisão que percebe, num mesmo mundo, mundos que a tradição ocidental (platônica) sempre viu separados; neste sentido, se, por um lado, a dobra separa os andares repercutindo dos dois 
lados, por outro, ela atua como o elemento de coesão entre os dois mundos da tradição, unindo-os num mesmo.

Mas, afinal, o que caracteriza a dobra no Barroco? Em primeiro lugar, o Barroco não inventou as dobras e, num certo sentido, qualquer articulação de dois elementos pode, em princípio, constituir uma dobra. Mas o que caracteriza a dobra barroca é que ela se multiplica ao infinito, dobra conforme dobra. Muitas são as imagens que Deleuze usa para ilustrar o que é uma dobra: as dobras do labirinto, do leque, dos tecidos, das formas esponjosas ou cavernosas e dos próprios elementos, como o filósofo aponta na pintura de El Greco. No entanto, a que melhor define a dobra é a linha de curvatura variável. Esta é uma linha que passeia espontaneamente e que, ao percorrer uma infinidade de pontos, pode compor uma superfície. Nela, cada ponto é composto por uma inflexão, uma espécie de ponto-dobra; a cada instante se diferencia, alterando seu grau de curvatura, ou seja, sua direção. É o fio que, dobrando-se ao infinito, compõe um tecido.
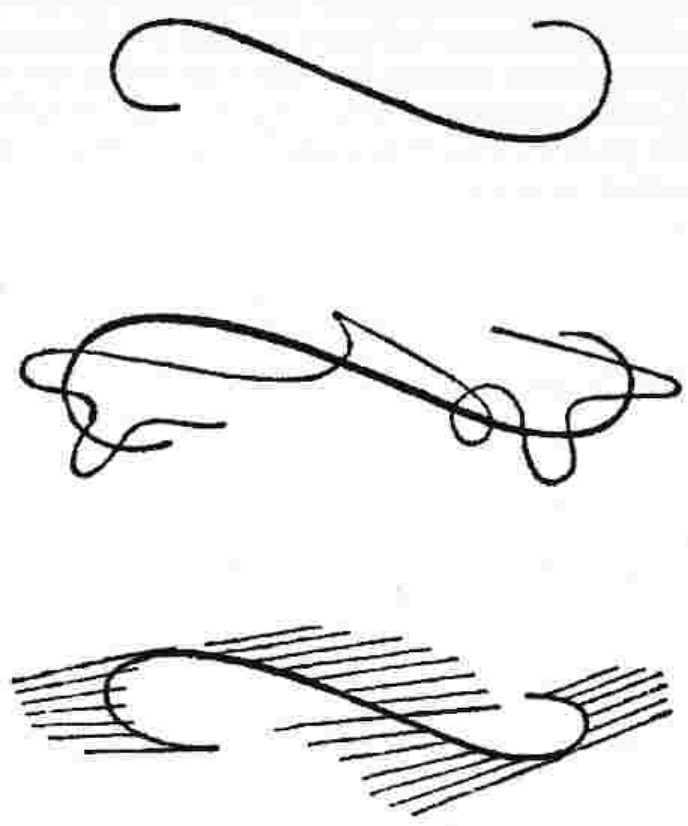

É na arquitetura e nas artes plásticas, contudo, que as dobras se evidenciam melhor. Deleuze chega a afirmar que as naturezas-mortas do Barroco têm como principal objeto as dobras, em lugar do referencial figurativo. São as mesmas dobras que compõem as vestimentas nos demais quadros do Barroco; “(...) ele [o Barroco] projeta mil dobras de vestes que tendem a reunir seus respectivos portadores, a transbordar suas atitudes e a ultrapassar suas contradições corporais (...).” (DELEUZE, 2007, p. 202) Tanto na reunião das personagens da pintura barroca, quanto no transbordamento de seus respectivos contornos, é muito significativo o papel da dobra enquanto elemento de coesão entre os dois mundos da tradição platônica, espiritualizando a matéria e, ao mesmo tempo, dando imanência a elementos que na tradição são figurados de maneira transcendente. Tomemos com exemplo a obra O Batismo de Cristo, do pintor maneirista El Greco. 


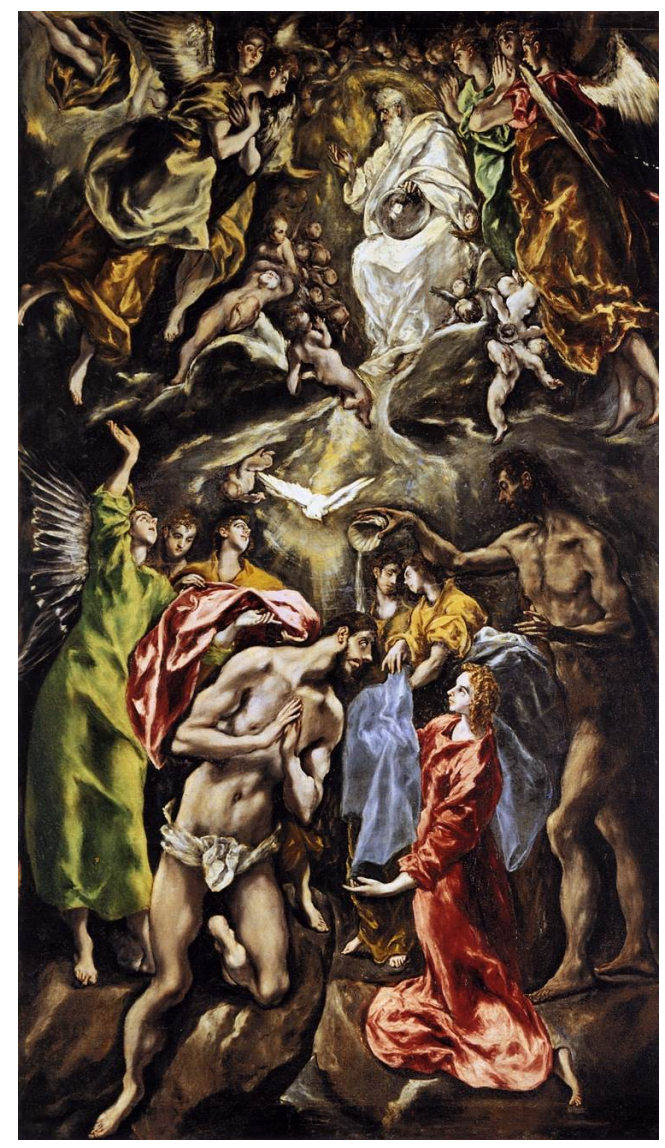

Nesta pintura observamos, em primeiro lugar, que o efeito das dobras das vestimentas é o de animar os corpos, nos dois sentidos da palavra: atribuilhes movimentação, mas principalmente expressa uma certa espiritualidade que lhes subjaz, já que as dobras, ao transbordarem os contornos, tendem ao infinito, tal como as terminações em voluta ou espuma, típicas da arquitetura barroca. Percebe-se que o próprio corpo descoberto do Cristo tem a mesma textura dos corpos vestidos a sua volta. Tal como afirma Deleuze, no Barroco

as dobras da vestimenta ganham autonomia, amplitude, e não apenas por um simples cuidado de decoração mas para exprimir a intensidade de uma força espiritual que se exerce sobre o corpo, seja para revertê-lo, seja para restabelecê-lo ou para elevá-lo, mas sempre para revolvê-lo e moldar seu interior. (DELEUZE, 2007, p. 203)

Em segundo lugar, estas dobras reúnem os corpos assim como os ligam aos elementos que os circundam: o solo e o elemento etéreo que divide os dois planos. Essa divisão, através da qual o plano celestial configura-se paralelamente ao terreno, com ele interagindo, é muito recorrente no Barroco. É nela que melhor se evidencia como o efeito estético da dobra se caracteriza por uma função de imanência: ela sobreimprime os planos, atravessando-os, tornando indiscernível o limite entre eles. Mesmo nos quadros em que a dobra não atravessa os dois planos nitidamente por estarem mais afastados entre si, tal como em As Sete Obras da Misericórdia, de Caravaggio, ela ainda atua como elemento coesivo e indiferenciador, pois os movimentos da linha de curvatura variável são, de um plano ao outro, retomados, neles repercutindo. Tal como uma voluta retoma um movimento iniciado em outro ponto e o estende ao infinito. 
Percebemos assim como a dobra, estendendo-se ao infinito em suas duas extremidades, expressa o imanentismo Barroco através de um duplo movimento entre os dois andares, transbordando os contornos e suportes. Deleuze assinala que essa autonomia adquirida pela dobra, conjugando os elementos figurativos ao invadir a superfície, caracterizará já não uma arte das estruturas, mas das texturas.

A concepção de escrita de Maria Gabriela Llansol é marcada pela oposição entre narratividade e textualidade. A narratividade corresponde ao diagnóstico de como, até então, o romance havia se desenvolvido. Segundo a autora, a experiência estética do contar histórias nos garantiria um certo alimento espiritual indispensável, o qual a narratividade encontra cada vez mais dificuldades em nos fornecer. Isto se dá porque ela é regulada pelo princípio de verossimilhança, subordinando o mito a uma racionalidade. As histórias assim remetem a um processo de fabulação virtualmente ilimitado, porém essencialmente repetitivo, visto seu encadeamento respeitar, em geral, princípios como os de não-contradição e de identidade. A ficção tradicional, portanto, estaria limitada por sua linguagem a abordar uma parcela relativa do real, o real-não-existente:

(...) está acontecendo há muito, que a narratividade perde o seu poder de fascínio. (...) por detrás das histórias, por detrás da magia do "era uma vez...", do exótico e do fantástico, o que nós procuramos são os estados do fora-do-eu, tal como a língua o indica, ao aproximar existência e êxtase, ao atribuir ao ser uma forma vibrátil de estar.

$\mathrm{Na}$ realidade, todos nós somos feitos, criados, longe, a distância de nós mesmos. (LLANSOL, 1994, p.119)

Essa aproximação entre existência e êxtase é fundamental para a compreensão da concepção de escrita e de mundo da autora, assim como a relação que os dois articulam. A partir daí, estabelece-se a oposição entre o real e o existente: o primeiro correspondendo tanto à realidade material quanto à ficção subordinada à racionalidade (um real que é ficcional e não suscita o êxtase ou, mais profundamente, que não possui existência justamente por não suscitá-lo); o segundo, à infinitude de nossa vida interior (que como a autora ressalta é criada longe, fora de nós) livre de diretrizes racionalizantes, assim como às virtualidades históricas inconclusas, já que a autora concebe o devir como simultaneidade (os tempos históricos ao invés de simplesmente sucederem linearmente, se acumulariam, carregando o presente dessas virtualidades).

Por sua vez, a textualidade, enquanto modelo de escrita proposto pela autora, compreenderia a abordagem do existente-não-real, em oposição ao realnão-existente da narratividade. Neste sentido, a textualidade desmascara as concepções transcendentalistas do real, denunciando-as como incapacidade da linguagem tradicional de nomeá-lo e atravessá-lo, que acaba por, desta forma, reduzido-lo. "Sem provocação, diria: a textualidade é realista, se se souber que, neste mundo, há mundos, e que ela os pode convocar, para todos os tempos, para além do terceiro excluído, e do princípio de não-contradição." (LLANSOL, 1994, p. 121) 
Llansol cria ainda uma série de conceitos que desenvolvem a noção de textualidade. Alguns aprofundam a oposição à narratividade, tais como imagem, que vem a substituir a metáfora, e figura, que se contrapõe ao conceito tradicional de personagem. Outros são conceitos desenvolvidos mais poeticamente, que abordam as relações entre a imaginação criadora, a escrita e o corpo; entres estes temos como exemplos metanoite, silêncio-onde e ponto-vora: O conceito que define, contudo, o produto de sua escrita é o de cena fulgor, que num certo sentido pode ser entendido como uma oposição à fabulação tradicional. Estas cenas se desenvolvem segundo um outro conceito que exprime de maneira mais geral a técnica de escrita da autora: a sobreimpressão.

A autora define-a de uma maneira curiosa, num texto intitulado $O$ Extremo Ocidental do Brabante (LLANSOL, 1994, p. 124-34), proferido na XI Bienal das Artes e da Cultura, dedicada a Portugal, em Bruxelas, 1991. Nele, Llansol narra duas situações de vida que se lhe impuseram de maneira, segundo ela, embaraçante, exigindo-lhe uma mutação de olhar - e consequentemente de linguagem - que resultaria na sobreimpressão: maneira pela qual a autora habita o mundo e técnica de escrita que passa a caracterizar sua obra a partir de O Livro das Comunidades. A primeira situação remete ao que antes chamamos de virtualidades históricas, segundo uma concepção do devir como simultaneidade; Llansol conta que, numa visita ao béguinage de Bruges, "de súbito, [teve] a sensação estranha de que vários níveis de realidade ali aprofundavam a sua raiz, coexistindo sem nenhuma intervenção do tempo." (LLANSOL, 1994, p. 126) O segundo caso narra uma experiência da autora como educadora. Por essa época, Llansol trabalhava numa escola alternativa e então se depara com o desafio de conduzir ao convívio e à fala uma menina com problemas de comunicação e suspeita de autismo. São as duas situações em que era preciso fazer falar, fazer com que a dobra atravessasse e unisse estes "vários níveis de realidade", que a linguagem (e o corpo, consequentemente) percorresse tanto as dobras da alma como as da história.

O que, tanto num caso como no outro, o que eu procurava sem o saber, era o logos, a que mais tarde chamei de cena fulgor o logos do lugar; da paisagem; da relação; a fonte oculta da vibração e da alegria, em que uma cena - uma morada de imagens -, dobrando o espaço e reunindo diversos tempos, procura manifestar-se.

(...)

Aprendi que o real é um nó que se desata no ponto rigoroso em que uma cena fulgor se enrola e levanta. (LLANSOL, 1994, p.128)

Nota-se, então, que a técnica de sobreimpressão visa reunir diversos planos, tal como os andares da casa barroca; ela constitui, sobretudo, uma linguagem que percebe o real através de dobras. São as dobras do tempo que percorrem o espaço num efeito de condensação, lembrando as dobras de um leque ou de fio enrolado em novelo. Esta noção da percepção do tempo enquanto uma realidade confirma-se no diário Finita: "Perscrutar e receber certas dobras quase gastas e apagadas de acontecimentos históricos." (LLANSOL, 1987, p. 29) Nota-se, ainda, na citação anterior, que o real é visto como um fio que tem seu nó desatado enquanto a cena se enrola, quando o verbo usual em português é desenrolar. Esse enrolar remete ao fio que, ao executar dobras, se condensa: a linha de curvatura variável. 
$\mathrm{Na}$ escrita de Maria Gabriela Llansol, o campo semântico do tecido é certamente um dos mais valorizados. O jogo de imagens que a autora através dele estabelece por si só constitui um elemento de coesão que sobreimprime os diversos "níveis de realidade", já que estes muitas vezes se configuram na linguagem através deste jogo, indiferenciando-se, como vimos no paralelo estabelecido entre o nó do real e o e o fio enrolado (condensado) do fulgor. Outros exemplos seriam: o xaile da mente, um conceito-imagem que a autora cria para a figura do pensamento; "Que linha do tempo ali foi quebrada?, mas não partida (...)" (LLANSOL, 1987, p.31),indaga Llansol numa entrada do diário Finita em que, mais uma vez, se vale do termo dobra para exprimir sua concepção de história; as diversas associações feitas entre a escrita e o bordar, ou o fazer renda, entre o texto e o tecido: a própria noção de textualidade que, por executar dobras que tendem ao infinito, marca o deslocamento de uma arte das estruturas (dos limites impostos pela narratividade) para uma arte das texturas. É através de uma proliferação de imagens que o fio do texto percorre as dobras dos diversos planos tradicionalmente separados.

Mas em que sentido este fio textual é de fato uma linha de curvatura variável, composta por inflexões, ou seja, uma dobra que vai ao infinito? Há um trecho particularmente interessante do diário Um Falcão no Punho, no qual a autora reproduz depoimentos dados em entrevista, nos quais a sua concepção de escrita aparece por demais associada ao conceito de dobra, que merece aqui alguns comentários.

O texto é a mais curta distância entre dois pontos.

Porque falamos, pensamos em novelo, e sentimos um emaranhado no estômago ou no coração. A palavra novela é a fuga a esta dor. Picada rápida ou encontro breve.

Não é porque as palavras estão deitadas por ordem no dicionário que imaginamos o texto liso, e sem relevo. Nós sentimos que as palavras têm normalmente a forma de esponja embebida ou, se se quiser, o relevo de pequenas rochas pontiagudas e reentrâncias ali deixadas pela erosão. (LLANSOL, 1998, p. 135)

Já na primeira frase, somos remetidos à linha de curvatura variável, pois é a dobra, ou seja, a inflexão, que encurta a distância entre os pontos, no processo de condensação que viemos caracterizando ao longo da exposição; além disso, fica clara a operação de coesão que a dobra exerce. Em seguida, o próprio pensamento é concebido enquanto dobra, em sua relação com a linguagem: "porque falamos, pensamos em novelo". O jogo de palavras entre novelo e novela, alude ainda à oposição entre narratividade e textualidade. A "picada rápida" sugere o efeito de identificação recorrente na narrativa tradicional, enquanto que o "emaranhado no estômago ou no coração" remete ao efeito de estranhamento característico da escrita da autora que, como vemos aqui, é uma vertigem causada pelas dobras, tanto na linguagem como no pensamento, análoga ao que se percebe com frequência nas artes plásticas do Barroco. No último parágrafo, a menção ao texto liso confirma a noção de textura em oposição a estrutura, que a dobra implica. As imagens da esponja e da rocha com reentrâncias são as mesmas utilizadas por Deleuze para ilustrar as dobras da matéria. 
Até aqui, tentamos demonstrar como, na escrita de Maria Gabriela Llansol, o real é concebido enquanto dobra, como seus diversos níveis são unidos (sobreimpressos) por ela, de que modo texto e pensamento correspondem a uma textura, cujo fio é uma linha de curvatura variável, linha composta por dobras que se estendem ao infinito. Vimos que a sobreimpressão também remete à infinitude da dobra, pois o real sobreimpresso é virtualmente infinito: tanto na sua dimensão histórica como na de nossa realidade interior. No entanto, para que a caracterização do fio do texto corresponda a esse movimento que tende ao infinito, é preciso demonstrar de que maneira ele percorre as dobras, passando de uma inflexão a outra.

Primeiro, observemos o exemplo da dobra que permanece aberta, tendendo ao infinito. É a elipse da linguagem que tem seu correlato na elipse barroca: dobra que transborda o contorno, remetendo para além dele; dobra que, como vimos, funciona como as terminações em voluta, crina de cavalo ou espuma, típicas da arquitetura barroca. $\mathrm{Na}$ escrita de Llansol, esse efeito tem uma representação especial: o traço contínuo

$\mathrm{Eu}$ pressenti em Johann, além da energia da vontade, uma vontade longínqua que se aproximava. Que velozmente se aproximava, e me perguntou: - Quando vem viver connosco? Eu ainda me encontrava em Lisboa, a tratar de uma mudança, a tentar fechar uma casa, a pegar todos os dias Témia pela mão, e levá-la não soube o que responder, não quis responder e a sala de jantar esvaiu-se. (LLANSOL, 1999, p. 2)

No entanto, este efeito não tem por objetivo simplesmente elidir um termo, mas sugerir ao pensamento (ao leitor) um movimento que segue indefinidamente. Se considerarmos como, na visão da autora, pensamento e linguagem estão sobreimpressos, indiscernindo o limite entre o sensível e o inteligível tal como nos dois andares da casa barroca, o traço contínuo pode também ser entendido como um índice desta sobreimpressão, pois nem sempre ele é utilizado para elidir um elemento sintático, mas obriga o pensamento que acompanha a escrita a uma suspensão. “(...) as torres tinham uma bela estatura de músico, confirmando as vozes que emudecem, ou traduzem, literalmente quem __é mudo." (LLANSOL, 1994, p. 20) O traço contínuo também é comumente utilizado para iniciar fragmentos do texto, apontando assim para um pensamento que extrapola os limites da escrita, tal como na abertura de Lisboaleipzig 1: O encontro inesperado do diverso: "_ ao lado da minha mesa de trabalho, está a mesa onde Bach poderia ensinar crianças(...).” (LLANSOL, 1994, p. 9) Este traço contínuo, portanto, não marca uma pausa musical, mas suspensão do pensamento que o dirige ao infinito. Para algo mais próximo de uma pausa musical a autora usa quebras de linhas, que num certo sentido aproximam a prosa do verso, mas é necessário considerar que, na sua escrita, a fanopeia e a logopeia são mais valorizadas que a melopéia. "Ler alto está relacionado com acústica - ensinou-me Bach -, há ondas e vibrações na sua formação que nunca aparecem escritas. Mas eu não quero uma leitura que seja um recitativo." (LLANSOL, 1994, p. 11)

O traço contínuo mostra, contudo, apenas a extremidade do fio do texto, sua última inflexão, que aponta para o infinito. Resta ainda percorrer as dobras que compõem sua extensão. Como vimos, a cena fulgor, este "novelo emaranhado", é uma "morada de imagens": o movimento do texto que 
caracteriza a dobra é, basicamente, a passagem de uma imagem a outra. Já afirmamos anteriormente que o termo imagem tem um estatuto privilegiado na escrita de Llansol, pois remete a um dos conceitos que caracterizam a textualidade.

A oposição entre imagem (textualidade) e metáfora (narratividade) é uma das mais radicais que sua escrita propõe, por acusar limitações num dos recursos mais elementares da arte literária tradicional e constituir um índice de sua saída da escrita representativa. Llansol afirma que "a metáfora é uma pequena fuga, pequena chama que só permite a compreensão passageira do que está a ler." (LLANSOL, 1991, p. 24) Concorde-se ou não com o diagnóstico que Llansol faz da literatura em geral, sabe-se que as metáforas, dentro de um contexto cultural específico - mas que pode ser tão genérico como a "cultura ocidental" - sofrem um inevitável desgaste e uma incontornável dificuldade em renovar-se. Pensemos, por exemplo, na tradicional metáfora das rosas. Isto se dá porque a metáfora pressupõe um movimento que vai de uma imagem a um referente, um movimento de ida e volta, quase circular. Tomemos como exemplo esta comparação que aparece na Ilíada, na tradução de Haroldo de Campos:

Feito gavião montês, a mais ágil das aves, que, fulmíneo, cai sobre tímida columba, por baixo esta lhe escapa e ele, lançando guinchos, acomete-a de perto, ávido de apresá-la; assim, furioso, Aquiles voa reto sobre Héctor (...). (CAMPOS, 2002, p.367, vol. II)

Sempre que dizemos "Aquiles é um gavião" ou "Ana é uma flor", é sugerido ao pensamento um movimento semelhante ao que estes versos exprimem textualmente. É este movimento quase que circular - diríamos de uma linha curvatura invariável - que a metáfora pressupõe. Há um campo de associações que fica circunscrito por este movimento que invariavelmente retorna da imagem suscitada pela metáfora ao referente, delimitando-o. As tentativas de renovação da metáfora passariam desta forma, por uma distorção desse círculo, desenhando uma elipse - causando uma certa vertigem -, mas sem deixar de circunscrever um campo de associações, por retornar ao referente: "Seu corpo arderá para mim/ sobre um lençol mordido por flores com água." (HELDER, 2006, p. 17)

Já o movimento que caracteriza a imagem dentro da concepção de textualidade é essencialmente aberto, tal como a linha de curvatura variável nos esboços de Klee. Ela já não circunscreve um campo de associações que remete a um referente, mas o abre, pois ela é autônoma em relação ao referente - é o próprio referente:

O meu texto não avança por desenvolvimentos temáticos, nem por enredo, mas segue o fio que liga as diferentes cenas fulgor. Há assim unidade, mesmo se aparentemente não há lógica, porque eu não sei antecipadamente o que cada cena fulgor contém. O seu núcleo pode ser uma imagem, ou um pensamento, ou um sentimento intensamente afetivo, um diálogo. (LLANSOL, 1998, p. 130-131) 
O movimento que a sucessão das imagens desenha - o percurso das dobras do fio do texto - não é, portanto, aleatório. É passagem de uma imagem a outra, sem aparente conexão de sentido, que nos traz a sensação do novelo emaranhado, num movimento de abertura de sentidos. Esta ausência de um encadeamento lógico tradicional é decorrente do processo de dobragem, pois a linha, ao ameaçar fechar um círculo deve proceder a uma inflexão, tal como afirma a autora claramente em um de seus diários: "Interrompo aqui o texto porque desliza para a metáfora." (LLANSOL, 1998, p. 32) Pois "O problema não é como findar uma dobra, mas como continuá-la, fazê-la atravessar o teto, levá-la ao infinito.” (DELEUZE, 2007, p. 66)

A inflexão, a unidade mínima da dobra, que em Llansol pode ser atribuída à passagem de uma imagem a outra, curiosamente "corresponde ao que Leibniz denomina 'signo ambíguo'. (...) ela é o próprio Mundo, ou melhor, seu começo, dizia Klee, 'lugar da cosmogênese'(...).” (DELEUZE, 2007, p. 33) Diríamos antes que esta inflexão, este ponto-dobra, seria o lugar do "encontro inesperado do diverso". É neste sentido, portanto, que a escrita de Maria Gabriela Llansol se caracteriza pela dobra que vai ao infinito, tanto por sua função de imanência que sobreimprime diversos níveis de realidade tornando indiscerníveis seus liames, como pela concepção da cena fulgor enquanto técnica literária.

\section{REFERÊNCIAS BIBLIOGRÁFICAS}

CAMPOS, Haroldo. Ilíada de Homero. São Paulo: Arx, 2002.

DELEUZE, Giles. A dobra: Leibniz e o Barroco. 4. ed. Campinas: Papirus, 2007.

HELDER, Herberto. Ou o poema contínuo. São Paulo: Girafa, 2006.

LLANSOL, Maria Gabriela. Finita. Lisboa: Rolim, 1987.

. Um beijo dado mais tarde. 2. ed. Lisboa: Rolim, 1991.

. Lisboaleiprig 1. Lisboa: Rolim, 1994.

. Um Falcão no Punho. 2. ed. Lisboa: Relógio D’água, 1998.

Lisboaleiprig 2. Lisboa: Rolim, 1999.

\section{REFERÊNCIAS ICONOGRÁFICAS}

Linha de curvatura variável: desenhos de Klee, reproduzidos de:

DELEUZE, 2007, p.32.

GRECO, El. O Batismo de Cristo (domínio público). In: http://upload.wikimedia.org/wikipedia/commons/d/d4/Image-

El Bautismo de Cristo El Greco version1609.jpg 